\title{
Theory and Methods of Research (or How to Be a Graduate Student)
}

\author{
Joseph H. Holles \\ Michigan Technological University, Houghton, Michigan
}

\begin{abstract}
Today's graduate students are coming from increasingly diverse backgrounds. This includes students who were in the work force for a few years, students with many years experience now seeking professional degrees, international students as well as conventional students directly from undergraduate programs. While this breadth of backgrounds can result in a vibrant program it also may result in a wide range of ideas about what graduate school actually entails and what is expected of the students.
\end{abstract}

To help address this problem, a graduate course titled "Theory and Methods of Research" has been developed and is now required for all chemical engineering graduate students. The goal of this course is to systematically present to the students many of the common situations that make up the graduate school experience. This includes communication skills such as outlines, abstracts, proposals, journal articles, and oral presentations. Research oriented topics include discussion of the scientific method, research methods and instruments, and critical reviews of journal articles. Professional ethics as a student and researcher are also discussed. Other informative lectures cover subjects such as copyright, patents, and research notebooks. One central theme in this course is for the students to communicate often and effectively with their advisor. Thus students receive initial exposure to many subjects critical to future success in a way that allows subsequent development by their faculty advisor.

In this paper, the structure and content of this course will be presented. In addition, methods for incorporating multiple topics in a single assignment will be suggested. Comments and feedback from both students and faculty advisors will also be discussed.

\section{Introduction}

In today's university, there are fewer and fewer "typical graduate students." Although some students do enter graduate school directly after completing their undergraduate program in the traditional manner, many do not. Alternatives include students working for a few years and then returning to graduate school, mid- or late-career professionals now seeking advanced degrees, and international students from numerous different countries. In addition, many traditional graduate students have their bachelor degrees in different disciplines. Many positives can result from this situation including a vibrant multi-generational and multi-cultural graduate program. However, it is also not without its shortcomings. Perhaps one of the most important issues to deal with is that a wide range of students can also result in a wide range of student concepts of and expectations for graduate school. 
In addition, our department had observed over a number of years that graduate students did not have the necessary skills to give a proper professional presentation. Clearly, the ability to give professional presentations is a necessity for graduate school (e.g., research group presentations, thesis proposals, regional and national meetings, final thesis defense). In addition, as future members of the work force with advanced degrees, these students will be expected to give professional presentations in their jobs. The initial approach of our department to address this problem was to require all incoming graduate students to give a formal department wide presentation during their first year. Unfortunately, this approach failed in short order since no one was responsible for ensuring that all students were indeed meeting this requirement. As such, another method was developed to ensure that our students were not only gaining experience in preparing and delivering professional presentations, but they were also being educated on how to prepare and deliver these presentations. From this original focus on presentation, the course has evolved to include other topics of interest to graduate students.

\section{Approach}

In the Department of Chemical Engineering at Michigan Technological University (MTU), we have developed a graduate course entitled "Theory and Methods of Research." This course is required for all chemical engineering graduate students. The class is offered during the fall semester and is typically taken during the student's first semester in graduate school. Theory and Methods of Research is for 3 credits and meets three days each week for one hour per meeting. During this semester, the students are also taking two other required graduate courses, Applied Mathematics for Chemical Engineers (3 credits) and Advanced Chemical Engineering Thermodynamics ( 3 credits), and are usually serving as a Teaching Assistant to an undergraduate course. Required graduate course account for 15 credits in our program and no course was deleted when this course was started. There are typically seven to thirteen students taking this class.

Currently, the major goals of this course are: 1) Equip the students with the skills and experience to prepare and present professional presentations, and 2) Present systematically many of the common situations that make up the graduate school experience. Although the original goal of the course was to better prepare students to present professional publications, this goal has grown to include equipping the students with a greater variety of the oral and written communication skills that they will require as a graduate student. These expanded goals fall into both of the major goals above.

While many other courses have been developed to help students both succeed in graduate school and prepare for future careers, these course are usually more narrowly focused than this class. For example, several courses have been developed to educate engineering students about learning processes and resources to help them in a teaching career ${ }^{[1,2]}$. In addition, a workshop has been developed to focus on major communications required to obtain an advanced degree in engineering $^{[3]}$; Lilja presented techniques for helping faculty teach the research process ${ }^{[4]}$; and Mullenax discussed common difficulties graduate students may encounter and possible actions to deal with them ${ }^{[5]}$. Many of the aspects of the course as discussed below are covered more completely in the above references. 


\section{Results and Discussion}

Theory and Methods of Research had been offered for two years previous to the author teaching the class. During this time, the general outline of the class was developed. The initial version of the class required the students to do two presentations. In addition, topics such as communications basics, presentation skills, how research is performed, and ethics were covered in lecture format. The author of this paper has now taught this class for three years. While the basic structure of the original class has been retained, additional topics and assignments have been included to more completely cover the graduate school experience. A typical class schedule is shown in Table 1.

Table 1: Typical Class Schedule

\begin{tabular}{|c|c|c|c|c|c|}
\hline Week & Class & Topic & Week & Class & Topic \\
\hline 1 & $\begin{array}{l}1 \\
2 \\
3 \\
\end{array}$ & $\begin{array}{l}\text { Welcome/Introduction } \\
\text { Library } \\
\text { Why Grad School? }\end{array}$ & 8 & $\begin{array}{l}1 \\
2 \\
3 \\
\end{array}$ & $\begin{array}{l}\text { Paper Writing } \\
\text { Paper Writing } \\
\text { Paper Writing }\end{array}$ \\
\hline 2 & $\begin{array}{l}1 \\
2 \\
3\end{array}$ & $\begin{array}{l}\text { Holiday } \\
\text { Communications Basics } \\
\text { No Class }\end{array}$ & 9 & $\begin{array}{l}1 \\
2 \\
3 \\
\end{array}$ & $\begin{array}{l}\text { Ethics } \\
\text { Ethics } \\
\text { Ethics } \\
\end{array}$ \\
\hline 3 & $\begin{array}{l}1 \\
2 \\
3\end{array}$ & $\begin{array}{l}\text { Presentations } \\
\text { Presentations } \\
\text { Writing Abstracts } \\
\end{array}$ & 10 & $\begin{array}{l}1 \\
2 \\
3\end{array}$ & $\begin{array}{l}\text { Student Led Ethics Discussions } \\
\text { Student Led Ethics Discussions } \\
\text { Student Led Ethics Discussions }\end{array}$ \\
\hline 4 & $\begin{array}{l}1 \\
2 \\
3\end{array}$ & $\begin{array}{l}\text { Copyright } \\
\text { Scientific Method } \\
\text { Scientific Method } \\
\end{array}$ & 11 & $\begin{array}{l}1 \\
2 \\
3\end{array}$ & $\begin{array}{l}\text { AICHE Conference } \\
\text { AICHE Conference } \\
\text { AICHE Conference }\end{array}$ \\
\hline 5 & $\begin{array}{l}1 \\
2 \\
3\end{array}$ & $\begin{array}{l}1^{\text {st }} \text { Student Presentation } \\
1^{\text {st }} \text { Student Presentation } \\
1^{\text {st }} \text { Student Presentation }\end{array}$ & 12 & $\begin{array}{l}1 \\
2 \\
3\end{array}$ & $\begin{array}{l}\text { Patents } \\
\text { Research Notebooks } \\
2^{\text {nd }} \text { Student Presentation }\end{array}$ \\
\hline 6 & $\begin{array}{l}1 \\
2 \\
3\end{array}$ & $\begin{array}{l}1^{\text {st }} \text { Student Presentation } \\
1^{\text {st }} \text { Student Presentation } \\
1^{\text {st }} \text { Student Presentation }\end{array}$ & 13 & $\begin{array}{l}1 \\
2 \\
3\end{array}$ & $\begin{array}{l}2^{\text {nd }} \text { Student Presentation } \\
2^{\text {nd }} \text { Student Presentation } \\
2^{\text {nd }} \text { Student Presentation }\end{array}$ \\
\hline 7 & $\begin{array}{l}1 \\
2 \\
3\end{array}$ & $\begin{array}{l}1^{\text {st }} \text { Student Presentation } \\
\text { Proposal Writing } \\
\text { Proposal Writing }\end{array}$ & 14 & $\begin{array}{l}1 \\
2 \\
3\end{array}$ & $\begin{array}{l}2^{\text {nd }} \text { Student Presentation } \\
2^{\text {nd }} \text { Student Presentation } \\
2^{\text {nd }} \text { Student Presentation }\end{array}$ \\
\hline
\end{tabular}

Reference information for the class comes from a wide variety of sources. However, two books have been selected as required. The two texts central to the entire class are "A Ph.D. Is Not Enough" by Peter J. Feibelman ${ }^{[6]}$ and "Graduate Research" by Robert V. Smith ${ }^{[7]}$. These two books are required since they cover many of the topics that are discussed in class and they can also continue to serve as handbooks for the students throughout their graduate and professional careers. In addition, all students are provided with a copy of "On Being a Scientist: Responsible Conduct in Research" by the Committee on Science, Engineering, and Public Policy of the National Research Council ${ }^{[8]}$. 
To start off the class and the school year, I usually begin with a lecture titled "Why Graduate School?" Since the students are already attending graduate school, this discussion may appear to be too late. However, many of the students still have questions in their minds about why they are attending graduate school. This lecture discusses several typical reasons why students attend graduate school. By revisiting these reasons and allowing the students to voice their own reasons, the students reinforce in their minds why they are attending graduate school. During this lecture, we discuss some of the benefits of graduate school including what graduate school can do for the student and also what graduate school will not do. We also discuss some of the different components of graduate school such as class work, seminars, teaching assistanceships, and research. This lecture also provides an opportunity to discuss a few of the career options available to students once they have completed a graduate degree. Finally, the class is concluded by a short discussion of the topics for the upcoming term and the goals of the class.

The second class of the term focuses on library usage. For this lecture, I turn the class over to a reference librarian. This class serves to acquaint students who were not MTU undergraduates and also re-exposes MTU undergraduates to our library and the specific search engines and databases available to them. The librarians also make the lecture discipline specific by focusing on topics relevant to chemical engineers (e.g. SciFinder Scholar).

First Presentation: The work required to complete the first student presentation is broken down into four separate assignments. To initiate this preparation, the next course topic is communication basics. Since this topic applies to all types of communication subsequently discussed in the course (outline, presentation, and proposal), it is necessarily broad. The communication focus this early in the course is on writing a memo. Students that have had previous industrial experience can provide valuable input at this point. They usually have examples of both good and bad memos. In addition, students are more likely to listen to their classmates than the instructor. Focusing on the basics of a memo leads into Assignment 1 (all assignments are summarized in Table 2). The first assignment in the class is to prepare a memo discussing five research methods, instruments, and techniques that will be useful to the student's graduate research. This is the first example of using the class to encourage the students to think about their research and to talk to their advisor. Since student-advisor pairings are made during the admissions process, all students have a designated advisor prior to the start of classes.

Table 2: Assignments

\begin{tabular}{|l|l|}
\hline & \\
\hline 1 & Research Methods, Instruments, and Techniques Memo \\
\hline 2 & Topic Selection and Outline Preparation \\
\hline 3 & Abstract of Presentation \\
\hline 4 & Research Methods, Instruments, and Techniques Presentation \\
\hline 5 & Written Grant Proposal \\
\hline 6 & Classroom Ethics Discussion \\
\hline 7 & Critical Review of Journal Article \\
\hline
\end{tabular}


The memo and list of five research methods, instruments, or techniques also serves as the basis for next three assignments. I compile a master list of all the topics mentioned in the memos and note the most frequently listed and widely applicable topics. This list is then presented to the class and each student selects one of the topics. The selected research method, instrument, or technique then becomes the subject of the first presentation. At this point I hand out Assignment 2. For Assignment 2, the students prepare an outline of the topic they have selected for their upcoming presentation. In this manner the students are required to both learn about their topic and break down what they wish to talk about. In addition, library skills are reinforced since the students must use the library to obtain information for their presentation.

While the students are researching their chosen technique and developing a presentation outline, several lectures are devoted to the scientific method. While most of the other topics in this course focus on research methods, this set of lectures introduces theory into the course. In addition, this topic does not have an associated assignment. These lectures are developed from the corresponding material in Feibelman ${ }^{[6]}$ and Smith ${ }^{[7]}$ along with "The Craft of Research" by Wayne C. Booth, Gregory G. Colomb, and Joseph M. Williams ${ }^{[9]}$. The scientific method includes: Observation, Hypothesis, Experimentation, and Interpretation. Although this appears simple at first, observation and hypothesis are usually done in advance by the advisor and the student often comes on board for the experimentation and interpretation steps. Thus, it is important to spend some time educating the students about the entire process. The discussion of experimentation is very open ended since it can include a wide variety of topics including statistical analysis and design of experiments. An outside lecture on either of these topics can be very beneficial.

Once the outline is complete, the students begin to prepare their presentation. In parallel the students also prepare an abstract of their talk. The abstract is Assignment 3 for the class. Prior to the assignment, one class period is devoted to writing abstracts. Since there are many different types of abstracts, the ones most relevant to graduate school are focused on. These include: journal article, presentation, and proposal to present. In this situation, the students obviously prepare an abstract for their presentation. Since the research method, instrument, or technique may be of interest to others outside of class, I email the abstract to all the faculty and graduate students in the department.

Assignment 4 is to actually prepare and deliver the presentation on their chosen topic. In this way the student learns about the research method, instrument, or technique and also educates other students in the class about the topic. A major benefit of this approach is that the students can be exposed to a number of topics in a time efficient manner. Once again, we spend at least two days prior to the presentation covering the dos and don'ts of presentations. One example that I have found extremely practical and useful is by Prof. Hans Niemantsverdriet and is available through the European Federation of Catalysis Societies homepage (http://www.efcats.org/). In addition, a more thorough treatise on preparing scientific presentations is found in "The Craft of Scientific Presentations" by Michael Alley ${ }^{[10]}$. I usually schedule one student presentation per day. However, if the class size exceeds eight students, scheduling two per day is necessary to allow time for covering other topics. One of the requirements for this assignment is to include a detailed example of how the research method, instrument, or technique is used to solve a current research problem of interest. Again, this 
requirement allows the students to integrate their research into the coursework. When the students deliver their presentation, their fellow students help with the evaluation. Prior to each presentation, I use an advance copy to prepare a short true/false and multiple choice quiz. This quiz is an attempt to gauge the ability of the presenter to convey knowledge about their topic. The class is free to fill in the answers to the quiz at any time during the presentation. In addition, each student in the class completes a peer evaluation of the presentation. Since different people focus on different things, a large number of comments are developed. I also prepare my own evaluation. All evaluations are shown to the presenter as a feedback mechanism.

The short quizzes are a holdover from the previous instructor. However, after several years of teaching the class, the benefit of the short quizzes is unclear. Although intended to determine how well the topic was presented, it may depend more on my quiz writing ability. It also results in the students being more focused on answering the quiz questions than evaluating the overall effectiveness of the presentation. In an attempt to minimize this concern, I have made the quiz a very small portion of the grade. Perhaps a better approach would be to have the presenter prepare the quiz. This would force the student to really focus on the core concepts they are trying to communicate and then they could get direct feed back on how well they did.

Peer evaluations of the presentation tend to be more based on instinct and instructor evaluations tend to be more technical. On a grading scale of 0 to 100 , I am consistently 6 to 8 points tougher than the students. Again, this may result from the students focusing on the information while I can focus on the mechanics of the presentation. It is also encouraging that, to date, I have not graded a student well only to have the peer evaluations be lower. I originally did not include a peer evaluation of the second presentation. However, students tend to listen to feedback from their peers a little better than from me. In addition, it does force them to pay attention to the speaker. Most importantly, by doing a peer evaluation, they are forced to consider what the speaker is doing and if they could somehow do it better.

One of my main observations from both this presentation and the journal review presentation (to be discussed) is that they are too short. If I assign a 35-40 minute presentation, the average length is only 25 minutes and rarely does any one exceed 30 minutes. This assignment is an attempt to mimic a professional conference where your presentation time slot is fairly rigid. I emphasize to the students that they need to practice in advance and time themselves and adjust the length of their presentations accordingly. However, they universally come up short. While I recognize that professional conference presentation are rarely this long, my experience indicates that 35-40 minutes is an appropriate length of time to provide the basics and thoroughly discuss an example. In an attempt to address this problem, I will review the complete presentation several days in advance and provide feedback to the students indicating if the presentation length is appropriate.

Proposal Writing: Once the first presentation is complete, the classes focus shifts from oral to written communication. For assignment 5, the students select a source and apply for funding to support their graduate studies. First, the student must identify a potential funding source. Again, they are encouraged to discuss this with their advisor. Once identified, the assignment is to complete all necessary applications and forms not only for the funding agency but also any forms required by the research and sponsored programs office of our university. 
Although this type of written communication was not part of the original course concept, it was added as a result of student and advisor evaluations and feedback. To prepare the students to write their proposals, I turn to an outside expert for help with the lectures. We are fortunate to have a person in the research and sponsored programs office whose job it is to help others prepare grant applications. Since she is an expert in the area and has reviewed many applications, she can provide invaluable advice. In addition, since she is not the instructor, the students are quite willing to take her advice. If such as expert is unavailable to you, similar material can be found in "Getting Science Grants" by Thomas R. Blackburn ${ }^{[11]}$. Once the students have completed the assignment, there is very little additional work required to actually submit the proposal and so many students do. One drawback to this approach is that for many of the common graduate school fellowships available, students must be U.S. citizens to apply. Unfortunately, this eliminates the international students. Although I have encouraged these students to look for other sources of funding for which they are eligible, we have not been able to identify any. Student effort for the last step does not go unrewarded since the graduate school will give the students $\$ 100$ for each proposal they submit.

Paper Writing: The second major topic of the term without an assignment is writing papers. Again, this topic can be covered while the students are completing their proposals and starting work on their final presentation. This set of lectures is broken into two main topics: 1) the mechanical and descriptive process of preparing a paper for publication and of the sections of a paper, and 2) my personal approach to how I write papers. Of course, I always conclude with the fair warning that other advisors may not write papers in the same manner and I encourage the students to learn how their advisors write papers by both reading previous work and talking to them.

In the first portion of this subject, we discuss why papers are written (e.g., sharing research findings, allowing others to build upon results, gaining tenure, and evidence to funding agencies of progress) and the mechanics of manuscript submission from selecting a journal to ordering reprints. We also discuss the different types of journal articles such as communication, regular article, note, review, or letter. This also provides a good opportunity to discuss journal hierarchy and the journal's impact factor. This section is concluded by examining the sections of the paper (e.g., title, abstract, introduction, etc.) individually and discussing the importance and reason for each section.

In the second portion of this subject, I present my personal approach to paper writing and what I like to see and not see in each section of the paper. Although my approach of starting with the experimental section and proceeding through the results, discussion, introduction, conclusions, and ending with the abstract is not original, it is at least a method the students can fall back on when necessary. This is also a good point in the course to discuss authorship issue involved with journal articles. A little groundwork here will pay off later during the ethics discussion (viz. the J.H. Schon affair). Both the American Chemical Society (http://pubs.acs.org/about.html and click on "Ethical Guidelines") and the American Physical Society (http://www.aps.org/statements/02 2.cfm) have guidelines on the responsibilities of coauthors and collaborators. Finally, the students are encouraged to read and follow the instructions for authors prepared by the journal editors. 
Ethics: For the ethics section, the initial classroom lecture focuses on some of the common ethical situations in science and engineering. These include plagiarism, data manipulation, authorship issues, and grant and manuscript review. Data manipulation is further elaborated upon by breaking it down into three categories: Trimming, Cooking, and Forging. The students at this point read "On Being a Scientist: Responsible Conduct in Research" and discuss the nine hypothetical scenarios presented within. These scenarios are excellent since they focus on many of the big picture issues such as data manipulation and conflict of interest specifically from the graduate student perspective. Each of the scenarios provides several questions at the end to initiate the classroom discussion. The booklet also contains an appendix with a short discussion of how the situation discussed in each scenario can be addressed or further explored. I withhold the appendix from the students until after the discussion in order to encourage them to come up with their own ideas. Many additional vignettes can found in "The Ethical Chemist" by Jeffrey Kovac ${ }^{[12]}$. Typically, two class periods are required for discussion of all the scenarios in this booklet.

At this point, each student leads a short classroom discussion of an important current ethics issue in science and engineering (assignment 6). The short scenario and question style of the National Research Council booklet serves as an excellent template for the students preparing the classroom discussions. Topics for the student lead discussions have include the J.H. Schon events at Bell Labs, the Baltimore Case, and the Schwartz/Mirkin authorship issue. I suggest a possible list of topics for the students since they may not be familiar with many of the current issues, but they are also free to select their own topics. When evaluating this assignment, I look at several aspects including background material, synopsis for the class, and the classroom discussion. For the background material: Have they obtained a copy of the original document (if appropriate) and also several outside discussions and commentaries on the issue? For the synopsis: Is it thorough and yet concise? Does is mention several issues to initiate discussion? For the classroom discussion: Is a more complete background provided? Has the student developed appropriate ethical questions relevant to the topic and considered several possible alternatives and resolutions to the issue? This assignment also has the students doing more literature searches and reinforcing library skills. Finally, although less formal than the other two presentations, this is another opportunity to build upon their presentation skills.

Second Presentation: The concluding topic for the course is a critical review of a journal article (Assignment 7). This topic serves as a good choice for a final assignment since it involves a number of the topics that have been previously covered in class. These topics include writing abstracts, writing journal articles, data presentation, scientific method, and even ethics. The students are free to select any article of their choosing for this review. I suggest that they select a manuscript relevant to their research. Again, discussion with an advisor can help select an appropriate article. The students have now covered the scientific method and paper writing and thus have sufficient knowledge to lead to a fairly in-depth critical exam of the journal article. The students are free to critique anything about the article including the layout and the typesetting. While the authors of the article do not have much control over these issues, the students learn a little more about the process of publishing an article. Since the student has received feedback on their first presentation, I also review the comments from that presentation to see if they have made changes and improvements. I am also looking forward to the day when 
a self-motivated student selects one of my journal articles as the subject of their critical review. I am sure they will find all of my mistakes.

Interspersed throughout the course are additional topics useful to graduate students. These topics are all stand-alone and can be moved around as necessary to adjust the class schedule. These topics include copyrights, patents, and research notebooks. The prospective lawyers in the class usually enjoy copyrights and patents. If you cannot find someone who has recently been involved in a patent filing, the book "Patent Fundamentals for Scientists and Engineers" by Thomas T. Gordon and Arthur S. Cookfair is an excellent resource ${ }^{[13]}$. Before discussing research notebooks, it is worthwhile to do a little research and determine if the university, college, or department has developed a set of guidelines for notebooks. The increasingly stringent guidelines on federally funded research may have resulted in your university developing such material. In addition, the classes on copyrights and patents present additional opportunities to bring outside speakers into the classroom. The students will greatly appreciate the advice and experience presented by someone who has recently filed a patent.

Throughout this class, two additional major concepts are continually reinforced. First, as graduate students, it is necessary to talk to your advisor and discuss what you are doing and why you are doing it. Too many students of all backgrounds seem to maintain an undergraduate relationship with their professor and only talk to them when they have a problem. Many of the exercises in this class are specifically designed to encourage advisor/student interaction.

Second, the students need to understand what a graduate education entails. Many faculty members would agree with the statement that it is the student's degree and not theirs. If the students understand what they must do to attain their graduate degree and take ownership of that degree, it will be more valuable to them. To encourage this concept, this class attempts to cover many topics important to graduate school success that are not covered in other formal courses

Feedback: In general, feedback from both the faculty and students has been extremely positive. Faculty member have specifically noted the students have indeed improved their presentation skills across the board thus meeting the original goal of this class. In addition, they have noted that students are better able to digest literature articles and extract critical information. Finally, the faculty state that students have shown an improved understanding of the research process allowing them to get organized and more quickly proceed through the background research of their project.

In line with the course goals, the students also state that the class has improved their presentation skills. The students also demonstrate enthusiasm for the lectures on copyrights, patents, and ethics. Finally, the students have indicated that the assignment they like the most and learn the most from is the critical journal article review (assignment 7). Most students also cite this assignment as most useful when performing future research.

\section{Conclusion}

Although this class has evolved in many ways from what may in retrospect be viewed as a very ill-defined class, it has stayed true to its original goal of preparing students to give 
professional presentations. However, this concept of effective oral communication has served as the foundation for growth in other topics of both oral and written communication that are vital not only in graduate school but also in the professional world. In addition to communication skills, other topics vital to obtaining the full graduate school experience can also be readily included within the boundaries of this course.

\section{Bibliography}

1. Bates, R.A. and A.R. Linse. Preparing Future Engineering Faculty Through Active Learning. in Proceedings of American Society for Engineering Education Annual Conference 2003. Nashville, TN: ASEE.

2. Wankat, P.C. and F.S. Oreovicz. An Education Course for Engineering Graduate Students. in Proceedings of the American Society for Engineering Education Annual Conference 1999. Charlotte, NC: ASEE.

3. Alford, E.M. and P.E. Stubblefield. Mentoring Engineering Graduate Students in Professional Communications: An Interdisciplinary Workshop Approach. in Proceedings of the American Society for Engineering Education Annual Conference 2002. Montreal: ASEE.

4. Lilja, D.J. Suggestions for Teaching the Engineering Research Process. in Proceedings of the American Society of Engineering Education Annual Conference 1997. Milwaukee, WI: ASEE.

5. Mullenax, C. Making Lemonade - Dealing with the Unknown, Unexpected, and Unwanted During Graduate Study. in Proceedings of the American Society for Engineering Education Annual Conference 2004. Salt Lake City, UT: ASEE.

6. $\quad$ Feibelman, P.J., A Ph.D. Is Not Enough. 1993, Reading, MA: Perseus Books.

7. Smith, R.V., Graduate Research A Guide for Students in the Sciences. Third ed. 1998, Seattle WA: University of Washington Press.

8. Committee on Science, Engineering, and Public Policy, On Being a Scientist; Responsible Conduct in Research. 1995, National Research Council: Washington DC.

9. Booth, W.C., G.C. Colomb, and J.M. Williams, The Craft of Research. Second ed. 2003, Chicago IL: The University of Chicago Press.

10. Alley, M., The Craft of Scientific Presentations; Critical Steps to Succeed and Critical Errors to Avoid. 2003, New York NY: Springer.

11. Blackburn, T.R., Getting Science Grants; Effective Strategies for Funding Success. 2003, San Francisco CA: Jossey-Bass.

12. Kovac, J., The Ethical Chemist; Professionalism and Ethics in Science. 2004, Upper Saddle River NJ: Pearson Education.

13. Gordon, T.T. and A.S. Cookfair, Patent Fundamentals for Scientists and Engineers. Second ed. 2000, Boca Raton FL: Lewis Publishers.

\section{Biographical Information}

Joseph H. Holles is Assistant Professor of Chemical Engineering at Michigan Technological University. He received his BS in Chemical Engineering in 1990 from Iowa State University and his ME and PhD from the University of Virginia in 1998 and 2000, respectively. His research area is nanoscale materials design and synthesis for catalytic applications with an emphasis on structure/property relationships and in-situ characterization. 